\title{
Gestão empresarial e tecnológica em três clusters moveleiros selecionados no sul do Brasil
}

\author{
Entrepreneurial and technological management in three selected \\ furniture clusters in southern Brazil
}

\author{
Marcia Regina Gabardo da Camara ${ }^{1} ;$ Lauro Serconi $^{2}$
}

\begin{abstract}
Resumo
O objetivo do artigo é estudar os pólos moveleiros do sul do Brasil e analisar as estratégias de crescimento, inovação e de gestão empresarial para que seja dado identificar as semelhanças e diferenças no desenvolvimento recente e nas formas de gestão. O trabalho trata dos clusters moveleiros de Rio Negrinho (SC), Bento Gonçalves (RS) e Arapongas (PR) e seus objetivos são: a) identificar as estratégias competitivas, as estratégias de inovação adotadas pelas empresas que compõem os clusters; e as características da gestão tecnológica; b) levantar as sugestões de políticas públicas para o setor moveleiro; c) traçar um comparativo entre os três clusters moveleiros, comparando estratégias adotadas, gestão tecnológica e necessidades de cada cluster, e verificar se há possibilidades de formação de clusters avançados. A indústria moveleira brasileira desenvolveu-se pela formação de clusters. Em diferentes regiões do país, ela iniciouse com pequenas marcenarias, em produção ainda artesanal, depois evoluiu para a produção em série e tornou-se importante pólo de desenvolvimento, que alimenta a economia local e regional brasileira. Os pólos moveleiros selecionados para o estudo - Rio Negrinho (SC), Bento Gonçalves (RS) e Arapongas (PR) - salientam-se no desenvolvimento regional da Região Sul do Brasil e estão entre os dez maiores do país.
\end{abstract}

Palavras-chave: Indústria moveleira. Competitividade. Cluster.

\begin{abstract}
The purpose of this work is to study the most important furniture manufacturing districts in Southern Brazil and analyze the increase, innovation and management strategies in order to identify similarities and differences in the recent development and forms of management. This work deals with the furniture clusters of Rio Negrinho (SC), Bento Gonçalves (RS) and Arapongas (PR), with the following specific purposes: a) to identify competitive and innovation strategies adopted by the industries that are part of the clusters, as well as the technological management characteristics; b) to do a survey of the public policies suggestions for the furniture industries; c) to outline a comparison among the three furniture clusters, comparing the strategies adopted, technological management and each cluster's needs, and verify if it is possible to set up advanced clusters. Brazilian furniture industry has developed itself through clusters formation. In different regions of the country, it started as small carpentries, artisanly, and then it evolved to large scale production and became an important development district, which feeds the local as well as the Brazilian regional economy. The furniture manufacturing districts selected for this study - Rio Negrinho (SC), Bento Gonçalves (RS) and Arapongas (PR) - are considered extremely important in the regional development of Southern Brazil and are among the ten largest ones of the country.
\end{abstract}

Key words: Furniture industry. Competitiveness. Cluster.

\footnotetext{
${ }^{1}$ Professora Associada C - Docente do Depto de Economia UEL e PPA/UEM/UEL. E-mail:mgabardo@ sercomtel.com.br

${ }^{2}$ Mestre em Administração - PPA/UEM/UEL.E-mail:Iserconi@onda.com.br
} 


\section{Introdução}

A indústria moveleira é uma importante fonte de riquezas para as regiões onde está localizada e para o país. Gera grande quantidade de empregos, contribui para o desenvolvimento regional, e tem potencial para explorar o mercado externo, em função do seu potencial produtivo. Está dividida em pólos moveleiros concentrados nas Regiões Sul e Sudeste.

O objetivo deste estudo é estudar os pólos moveleiros do Sul do Brasil e analisar as estratégias de crescimento, inovação e de gestão empresarial, para que sejam identificadas as semelhanças e diferenças no desenvolvimento recente e nas formas de gestão. Os objetivos específicos do estudo dos clusters moveleiros de Rio Negrinho (SC), Bento Gonçalves (RS) e Arapongas (PR) são: a) identificar as estratégias competitivas, as estratégias de inovação adotadas pelas empresas que compõem os clusters e as características da gestão tecnológica; b) levantar as sugestões de políticas públicas para o setor moveleiro; e c) traçar um comparativo entre os três clusters moveleiros, comparando estratégias adotadas, gestão tecnológica e necessidades de cada cluster, e verificar se há possibilidades de formação de clusters avançados.

A indústria moveleira brasileira desenvolveu-se pela formação de clusters. Em diferentes regiões do país, ela iniciou-se com pequenas marcenarias, em produção ainda artesanal, depois evoluiu para a produção em série e tornou-se importante pólo de desenvolvimento, que alimenta a economia local e regional brasileira. Os pólos moveleiros selecionados para o estudo - Rio Negrinho (SC), Bento Gonçalves (RS) e Arapongas (PR) - salientam-se no desenvolvimento regional da Região Sul do Brasil e estão entre os dez maiores do país.

O artigo está dividido em seis partes: uma breve introdução, metodologia, referencial teórico sobre cluster, inovação e crescimento regional, indústria moveleira no Brasil, análise dos resultados dos pólos moveleiros no sul do Brasil e conclusão.

\section{Metodologia}

A pesquisa realizada classifica-se como um estudo formal que pretende responder à questão de pesquisa: quais são as assimetrias e semelhanças na trajetória de crescimento e acumulação regional dos clusters moveleiros do de Arapongas (PR) e região, Rio Negrinho(SC) e Bento Gonçalves (RS)?

O estudo é ex-post facto, pois os pesquisadores não controlaram as variáveis. A pesquisa é de natureza descritiva, transversal e estatística .As condições ambientais reais foram as dos pólos moveleiros de Arapongas (PR), Rio Negrinho (SC) e Bento Gonçalves (RS) e instrumentos foram aplicados aos respondentes, no seu horário de trabalho, no momento em que estavam desenvolvendo suas atividades nas empresas.

Para alcançar o objetivo geral do trabalho, estudar os diferentes pólos moveleiros e verificar assimetrias ou semelhanças na trajetória de crescimento e acumulação regional, optou - se, inicialmente, por realizar uma pesquisa bibliográfica para identificar os principais constructos e categorias teóricas e identificar variáveis de análise e indicadores de desempenho. Os estudos de Gorini (1998), Rosa (1999), Lins (2000) e Câmara et al. (2002) permitiram definir os objetivos específicos, pois identificaram os constructos gestão de produção - cujas variáveis estudadas envolviam controle de custo e qualidade de insumo, uso de normas administrativas e normas técnicas de produção - , gestão de inovação dividida em gestão de processo (novas máquinas) e gestão de produto (novos produtos, design e novos materiais) e seus determinantes.

O método de coleta de dados foi a pesquisa de campo; foi realizado o contato pessoal com os respondentes em Arapongas, e o telefônico, em Bento Gonçalves e Rio Negrinho. O questionário, composto por 42 perguntas foi construído para permitir a quantificação dos indicadores de desempenho e identificar semelhanças e diferenças entre os pólos. Ele foi composto por perguntas abertas e fechadas, adaptadas dos trabalhos empíricos 
(ROSA, 1999; CAMARA et al., 2002). Foi realizado o pré-teste para ajustar e calibrar as perguntas. As questões visam a levantar: a) características gerais da empresa pesquisada; b) tecnologia e gestão tecnológica; c) pesquisa e desenvolvimento; d) relação com fornecedores, clientes e mercado; e) visão estratégica; e f) sugestão de política pública para o segmento.

Para aplicar os questionários, utilizaram-se as listas de empresas cadastradas nos sindicatos dos três pólos moveleiros. A amostra foi selecionada por acessibilidade, seguindo a lista de empresas fornecidas pelos sindicatos. Esse questionário foi, primeiramente, aplicado a uma amostra de 45 indústrias do pólo moveleiro de Arapongas (PR), composto por um total de 140 indústrias cadastradas no SIMA. Foram pesquisados os gerentes administrativos e/ou proprietários de indústrias de empresas cadastradas no SIMA - Sindicato da Indústria Moveleira de Arapongas nas cidades de Arapongas, Londrina e Rolândia.

$\mathrm{Na}$ seqüência, realizou-se a pesquisa em uma amostra de 10 empresas do pólo moveleiro de Rio Negrinho (SC), composto por 48 indústrias cadastradas no Sindicato das Indústrias da Construção do Mobiliário de Rio Negrinho (SC), no período de maio a setembro de 2003. Por fim, pesquisou-se o pólo moveleiro de Bento Gonçalves (RS), composto por 71 indústrias cadastradas no SINDMÓVEIS, das quais foram selecionadas 15 empresas. A seguir, discutem-se os conceitos e teorias fundamentais para compreender a dinâmica setorial moveleira no Brasil.

\section{Indústria Moveleira: Cluster, Inovação e Crescimento Regional}

No início do século XXI, as empresas se defrontaram com um ambiente complexo, sujeito a incertezas que estimulou a formação de elos e o comportamento inovador. Fornecedores, clientes, parceiros, governo e as empresas ampliaram o grau de interação, trocando valores, produtos, serviços e informações. A proximidade geográfica de empresas setorialmente especializadas, especialmente de pequenas e médias empresas tem possibilitado um ambiente adequado para o desenvolvimento e fortalecimento das mesmas.

Clusters são " aglomerações territoriais de agentes econômicos, políticos e sociais, com foco em um conjunto específico de atividades econômicas, que apresentam vínculos mesmo que incipientes" (LASTRES; CASSIOLATO, 2003, p.11). Esse formato organizacional (cluster) é encontrado no mundo inteiro, mas é particularmente importante em regiões pouco desenvolvidas, com baixo nível de emprego, pois podem impulsionar o desenvolvimento da região onde está instalado. Para Lastres e Cassiolato (2003), a aglomeração de empresas e o aproveitamento das sinergias coletivas geradas por suas interações fortalecem efetivamente as possibilidades de sobrevivência e crescimento das empresas, e são forte geradoras de vantagens competitivas. Aaker (2001) diz que uma vantagem competitiva é criada com base em três fatores: base de competição, ativo e competência, onde a empresa compete e contra quem ela compete.

A alta competitividade enfrentada no setor moveleiro tem exigido das organizações a busca por caminhos alternativos e inovadores que as levem a conquistar resultados positivos. Um desses caminhos é a formação de clusters que, segundo Becattini e Rabelotti (apud LINS, 2000), são concentrações geográficas de firmas setorialmente especializadas, normalmente de pequeno e médio porte. A produção tende a ocorrer de forma verticalmente desintegrada porque elas se especializam em diferentes partes do processo produtivo. As relações fornecedores clientes reforçam os elos interfirmas nas diversas etapascadeia produtiva, estimulando as atividades cooperativas e a competitividade, mediante elos mercantis e não-mercantis.

Segundo Lastres e Cassiolato (2003, p.11), os arranjos produtivos locais: "são aglomerações territoriais de agentes econômicos, políticos e sociais - com foco em um conjunto específico de atividades econômicas - que apresentam vínculos mesmo que 
incipientes”. Em geral, envolvem a participação e interação de empresas como prestadoras de serviços, produtoras de bens e serviços finais, fornecedoras de insumos e equipamentos, entre outras. Elas incluem instituições públicas e privadas que formam a capacitação de recursos humanos (escolas técnicas e universidades), pesquisa, desenvolvimento e engenharia, política, promoção e financiamento.

Amato Neto (2000) diz que o conceito de cluster é entendido como a concentração setorial e geográfica de empresas, e somente quando as duas características são encontradas em conjunto ele recebe a denominação de cluster, de outra forma, o que se tem é apenas a organização de produção em setores e geografia dispersa. Para Lins (2000), a aglomeração representa o conceito de eficiência coletiva, pois muitas empresas do cluster são bem sucedidas, mas outras podem fracassar, uma vez que a ação conjunta entre as empresas viabiliza a solução de problemas específicos como infra-estrutura e treinamento. Porém a competitividade entre as empresas do mesmo cluster continua existindo, e a competência gerencial individual pode fazer a diferença fundamental.

Camara et al. (2002) afirmam que a análise de clusters permite o estudo de pequenas e médias empresas e reforça a capacidade de inovação via imitação em indústrias tradicionais, reforçando elos entre as firmas e entre as instituições. No mundo inteiro, verifica-se a instalação de blocos produtivos, com a participação de redes de fornecedores em torno dos empreendimentos âncoras, mas eles são particularmente importantes em regiões pouco desenvolvidas, com baixo nível de emprego, pois impulsionam o desenvolvimento da região onde estão instalados(LASTRES; CASSIOLATO, 2003) .

O cluster, além de concentração geográfica, é um conjunto de empresas e instituições inter-conectadas em um setor particular. Indústrias e outras entidades importantes para a competição como fornecedores de matéria-prima, componentes, serviços, equipamentos. São atores que compõem um cluster.
Podem ser incluídas instituições governamentais, empresas de treinamento, universidades e associações de empresas que proverão treinamento especializado, educação, informação, pesquisa e suporte técnico. Segundo Porter (1998, p.80), os limites de um cluster são definidos pelas ligações e complementariedades entre as indústrias e instituições mais importantes. A competição pode co-existir com a cooperação, pois ocorrem entre diferentes empresas e em diferentes dimensões e "um cluster de empresas independentes e informalmente ligadas, e instituições representa uma forma de organização robusta que oferece vantagens em eficiência, eficácia e flexibilidade."

As redes, arranjos e sistemas produtivos e inovativos, segundo Lastres e Cassiolato (2003), são os formatos organizacionais que se mostram mais adequados para a geração, a aquisição e a difusão de conhecimento e inovações. A competência competitiva das empresas depende da amplitude das redes em que participam, bem como da sua interação com as mesmas. A participação em redes possibilita às empresas complementarem-se umas às outras, nos aspectos técnicos e mercadológicos.

Segundo Pyke (1992), a rede é um sistema de cooperação entre empresas geralmente de pequenas empresas independentes, organizado em um local ou região como base, pertencendo ao mesmo setor industrial (incluindo todas as atividades upstream $\mathrm{e}$ downstream). Este tipo de cooperação facilita para o atendimento de inúmeras necessidades das empresas pertencentes ao mesmo conglomerado. Algumas dessas necessidades são: (1) combinar competências e utilizar know-how de outras empresas; (2) dividir o ônus de realizar pesquisas tecnológicas, compartilhando o desenvolvimento e os conhecimentos adquiridos; (3) partilhar riscos e custos de explorar novas oportunidades, realizando experiências em conjunto; (4) oferecer uma linha de produtos de qualidade superior e mais diversificada; (5) exercer uma pressão maior no mercado, aumentando a força competitiva em benefício do 
cliente; (6) compartilhar recursos, com especial destaque aos que estão sendo subutilizados; (7) fortalecer o poder de compra; (8) obter mais força, para atuar nos mercados internacionais.

Kanter (1990) aponta alguns tipos de alianças estratégicas possíveis de serem desenvolvidas pelas empresas, e essas alianças levam a um nível de cooperação interempresarial mais interessante para as partes envolvidas: alianças multiorganizacionais de serviços ou consórcios; alianças oportunistas ou joint ventures; e alianças de parcerias que envolvem fornecedores, consumidores e funcionários, na qual há um envolvimento de diversos parceiros (stakeholders) no processo de negócio, em seus diferentes estágios de criação de valor.

Para Roelandt e Hertog (1999), clusters diferem de outras formas de cooperação e network, uma vez que os participantes estão ligados em uma cadeia de valores. Não há apenas uma simples relação de trabalho horizontal como cooperação em P\&D e em marketing coletivo. Clusters são freqüentemente inter-setoriais (vertical e horizontal), compostos de firmas complementares em torno de uma específica linha de conhecimento na cadeia de valores. Inovações são estimuladas por relações horizontais, porém relações verticais entre fornecedores, produtores e usuários são igualmente importantes para a criação de inovações.

Para Porter (1998), clusters afetam a competição em três formas mais amplas: (1) por incrementarem a produtividade de empresas baseadas na área; (2) por conduzirem a direção e a velocidade da inovação, que guia o crescimento da produtividade; (3) por estimularem a formação de novos negócios, o que permite ao cluster crescer e se fortalecer. Outra característica positiva dos clusters é que os governos tendem a fazer investimentos em infra-estrutura e educação, o que influencia diretamente a produtividade das empresas. A produtividade determina a prosperidade de uma região ou nação. Daí a importância de ações por parte do governo para criar e aumentar a produtividade de sua região ou país. Políticas macroeconômicas são necessárias, porém são necessários alicerces microeconômicos para incentivar a competição e estimular a produtividade e a competitividade. Os governos (nacional e local) devem assegurar infra-estrutura e cidadãos capacitados para atuarem no desenvolvimento de uma região ou país.

Para Rosa (1999), o cluster avançado cuja referência é o modelo italiano, possibilita às empresas componentes desse cluster beneficiarem-se das economias externas, pois, em função da proximidade entre os estágios da cadeia produtiva consegue-se economia nos custos de transação (maior circulação de informações, transporte, contatos face-a-face).

Para gerar inovações, é necessária a aquisição e a difusão de conhecimentos. Segundo Foray e Lundvall (1996), há duas perspectivas na economia baseada no conhecimento, que não são mutuamente exclusivas. A primeira refere-se à identificação de um setor separado que produz novos conhecimentos ou distribui informações. Na segunda perspectiva, deve-se considerar a criação e difusão de conhecimento, a qual emana de atividades rotineiras na vida econômica e toma a forma do aprendendofazendo, aprendendo-usando e aprendentointeragindo. Know-how e competências têm sido desenvolvidos interativamente e partilhados em redes.

Edquist (2001) aponta as principais funções de um Sistema de Inovações(SI), que são em primeiro lugar, produzir, difundir e usar inovações e podem ser supranacional, nacional e subnacional (regional, local), e podem ainda ser setoriais dentro dessas demarcações geográficas. As organizações e instituições são os componentes principais de um sistema de inovação, porém a especificação desses componentes varia entre os sistemas. Organizações são estruturas formais com um objetivo explícito e são criadas conscientemente. Instituições são conjuntos de hábitos comuns, rotinas, práticas estabelecidas, regras, ou leis que regulam as relações e inter-relações entre indivíduos e organizações.

Segundo Malerba (2002), os agentes que 
compõem um sistema setorial são organizações, que podem ser firmas e non-firms, e são caracterizados por processos de aprendizado específicos, competências, objetivos, estruturas organizacionais e comportamentos. Interagem por processos de comunicação, trocas, cooperação, competição, e suas interações são delineadas por institutos (regras e regulamentos). Os elementos básicos de um sistema setorial são: (1) produtos; (2) os agentes, firmas e non-firms, organizações de baixo (departamentos de P\&D), e alto nível de agregação (empresas de consultoria), e indivíduos; (3) o conhecimento e processos de aprendizado, que são diferentes entre os setores e afetam atividades inovativas, a organização e o comportamento das empresas e outros agentes dentro do setor; (4) as tecnologias, entradas, demanda e elos de relação e complementariedades, devem ser estáticos e ao mesmo tempo dinâmicos; (5) os mecanismos de interação dentro e fora das empresas; (6) os processos de competição e seleção; (7) as instituições, como padrões e regulamentos.

Para Roelandt e Hertog (1999, p.10) , a inovação não é percebida como um processo linear e sim como resultado de uma complexa interação entre os vários atores, envolvendo rotinas, normas, regras e leis. É preciso trocar informações e conhecimentos com clientes, concorrentes e fornecedores de equipamentos, serviços e matéria-prima.

\section{A Indústria Moveleira no Brasil}

A indústria moveleira brasileira tem evoluído bastante nos últimos anos, apesar de ainda estar em estágio inferior ao da indústria mundial, particularmente no que diz respeito à difusão de tecnologia. Na década de 90 , verifica-se forte investimento na renovação dos equipamentos utilizados na indústria moveleira. Os estados de São Paulo, Rio Grande do Sul, Santa Catarina e Paraná respondem por cerca de $82 \%$ da produção nacional. O consumo nacional é suprido basicamente pela produção interna, com baixo volume de importação de móveis. E os principais centros consumidores são as regiões Sul e Sudeste, com realce para São Paulo e região do $\mathrm{ABC}$, Belo Horizonte, Curitiba, Porto Alegre, Rio de Janeiro e Brasília, bem como suas regiões metropolitanas. (GORINI, 1998)

A indústria moveleira brasileira é formada por 13.500 micro, pequenas e médias empresas familiares, tradicionais e na sua maioria de capital nacional. São 10.000 micro-empresas (até 15 funcionários), 3.000 pequenas empresas (de 15 a 150 funcionários), e 500 médias empresas (acima de 150 funcionários). $\mathrm{O}$ faturamento da indústria de móveis brasileira aumenta 279\% em apenas 9 anos, em 1999 são exportados R\$3,7bilhões e em 2002, o valor salta para $\mathrm{R} \$ 10,3$ bi. Desse faturamento, $60 \%$ referem-se a moveis residenciais, $25 \%$ a móveis de escritório e $15 \%$ a móveis escolares, móveis para restaurantes, hotéis e similares.

Os principais estados exportadores são Santa Catarina, Rio Grande do Sul, Paraná e São Paulo. Em 2002, somente o estado de Santa Catarina foi responsável por $53,07 \%$ de toda exportação de móveis brasileiros, e isto se deve à própria vocação do pólo moveleiro desse Estado, e à estrutura de logística, em função do porto de Itajaí. O Paraná é responsável por 8,2\% e o (\%) e o Rio Grande do Sul por $27 \%$ das exportações brasileiras de móveis. Os principais pólos moveleiros do Brasil são Ubá(MG), Linhares e Colatina(ES), Votuporanga(SP), Arapongas( PR), São Bento do Sul e Rio Negrinho(SC) e Bento Gonçalves(RS)(GORINI, 1998).

O pólo moveleiro de Bento Gonçalves (RS) localiza-se na região serrana do estado. É constituído por 130 empresas e emprega 7.500 funcionários. Originou-se no final do século XIX, quando marceneiros imigrantes italianos começaram a produzir móveis artesanalmente. Há concentração na produção de móveis retilíneos de madeira, móveis de pínus e móveis metálicos. Sua produção é voltada para o mercado interno, porém contribui com $27 \%$ 
das exportações brasileiras de móveis, ocupando o segundo lugar entre os exportadores do país. O seu desenvolvimento deve-se em grande parte ao associativismo existente entre os empresários locais, herança da cultura européia. Essa articulação é responsável pela criação do CETEMO - Centro Tecnológico do Mobiliário e do curso superior de Tecnologia em Produção Moveleira da Universidade de Caxias do Sul.

O pólo moveleiro de São Bento do Sul e Rio Negrinho (SC) está localizado no Vale do Rio Negro e é composto pelos municípios de São Bento do Sul, Rio Negrinho (SC) e Campo Alegre. É constituído de 210 empresas que empregam 8.500 funcionários. É o maior exportador de móveis do país, respondendo por 53\% das exportações brasileiras de móveis. Surge na década de 50, com imigrantes alemães, e na década de 70 assume papel de relevo na produção de móveis escolares e cadeiras de cinema.

O pólo moveleiro de Arapongas (PR) salientase pela produção de móveis populares - móveis retilíneos e estofados. É constituído de 145 empresas, que geram 5.500 empregos. Surge na década de 60 e sua produção é destinada principalmente ao mercado interno, e em menor escala, à exportação. Salienta-se um alto grau de associativismo entre os empresários, de que resultou em 1997, na construção de um grande centro de eventos, com mais de 20 mil metros quadrados, utilizado para feiras e eventos do setor, como a MOVELPAR - Feira de Móveis do Paraná. Merece realce também o CETEC, uma ONG criada pelos empresários para cuidar dos resíduos sólidos e líquidos da produção.

\section{Análise dos Resultados da Pesquisa sobre os Clusters Moveleiros no Sul do Brasil}

A seguir são apresentados e analisados os dados pormenorizados referentes à pesquisa de cada cluster: Arapongas, Rio Negrinho e Bento Gonçalves.

\section{Análise das Pesquisas do Cluster de Arapongas (PR)}

Das empresas pesquisadas, $61,36 \%$ atuam no mercado há mais de 10 anos, em média as empresas, têm 14 anos de atividade. Em 91\% das empresas o capital tem origem no próprio Estado e todas são de capital nacional. Os principais produtos das indústrias de Arapongas (PR) e região são armários $(19,8 \%)$, jogo de quarto $(19,8 \%)$, estofados $(16,7 \%)$, kits de cozinha $(15,1 \%)$, e rack/estante $(12 \%)$.

As vendas do produto principal representam mais de $60 \%$ do faturamento em $50 \%$ das empresas pesquisadas. Quanto ao total de funcionários nas empresas pesquisadas, $42,2 \%$ das empresas têm entre 5 a 19 funcionários, e 35,6\% têm de 20 a 99 funcionários. 73,3\% das empresas pesquisadas têm somente até 5 funcionários na área administrativa, $66,3 \%$ têm até 30 funcionários na produção. $\mathrm{Na}$ grande maioria, em $76,7 \%$ das empresas o faturamento é de até R\$ 12 milhões ao ano.

Quanto ao grau de instrução, 55,86\% do total de funcionários têm o segundo grau incompleto; $35,74 \%$ têm o segundo grau completo; $4,1 \%$ têm o superior incompleto; e 4,3\% têm o superior completo. As principais formas de treinamento nas empresas pesquisadas são: $25,5 \%$ no interior das empresas, $53 \%$ "on the job", $21,5 \%$ fora da empresa (especialmente no Senai e Sebrae). 31,1\% utilizam as normas técnicas (Associação Brasileira de Normas Técnicas -ABNT e INMETRO - e ISO9000); e 68,9\% têm conhecimento da existência dessas normas, mas não as utilizam.

As técnicas de organização da produção auxiliam a produtividade e qualidade no processo produtivo: em $93,7 \%$ das empresas pesquisadas ocorre a utilização de alguma técnica de organização da produção. As mais utilizadas são o círculo de controle de qualidade, a célula de produção e a polivalência nos postos de trabalho. Para resolver os problemas tecnológicos, 29,4\% das empresas utilizam pesquisa e desenvolvimento dentro da própria empresa; $27 \%$, os serviços de empresas de projeto e consultores nacionais, e 17,6\%, as Associações de Empresas. Quanto às condições atuais dos equipamentos, 75,6\% das empresas pesquisadas consideram que seus equipamentos estão parcialmente atualizados, e $89 \%$ julgam-se atualizados ou parcialmente atualizados. 
Os principais avanços tecnológicos identificados ocorridos ultimamente foram: a utilização de novas matérias-primas, a implantação de novos processos e novos equipamentos. O cluster de Arapongas (PR)

Quadro 1. Resumo da Análise do cluster de Arapongas (PR). e região caracteriza-se pelo processo de inovação incremental e as principais razões que induzem a inovação são a busca por redução de custo $(47,2 \%)$ e solicitações de clientes do mercado brasileiro $(41,5 \%)$.

\begin{tabular}{|c|c|}
\hline Principais Produtos: & $\begin{array}{l}\text { Armários, jogos de quarto, estofados, kits para cozinha (médios e } \\
\text { populares) }\end{array}$ \\
\hline Normas técnicas administrativas: & $\begin{array}{l}31,1 \% \text { utiliza alguma norma técnica } \\
\text { (principais: ABNT, ISO 9000) }\end{array}$ \\
\hline Normas Técnicas de Produção: & $\begin{array}{l}93,7 \% \text { utiliza técnicas de produção } \\
\text { (principais: círculo de controle de qualidade, célula de produção e } \\
\text { polivalência nos postos de trabalho) }\end{array}$ \\
\hline $\begin{array}{l}\text { Solução de problemas } \\
\text { tecnológicos: }\end{array}$ & $\begin{array}{l}\text { 29,4\% utiliza P\&D dentro da própria empresa; } 27 \% \text { serviços de } \\
\text { empresas de projeto e consultores nacionais; } 17,6 \% \text { Associações de } \\
\text { empresas. }\end{array}$ \\
\hline $\begin{array}{l}\text { Condições atuais dos } \\
\text { equipamentos: }\end{array}$ & - 89\% consideram entre atualizados e parcialmente atualizados. \\
\hline Origem dos equipamentos & - $42 \%$ do próprio estado \\
\hline $\begin{array}{l}\text { Principais obstáculos para o } \\
\text { avanço tecnológico: }\end{array}$ & $\begin{array}{l}\text { - insuficiência de incentivos fiscais e financeiros } \\
\text { - dificuldade de acesso a investimentos financeiros }\end{array}$ \\
\hline Principais avanços tecnológicos: & $\begin{array}{l}\text { - utilização de novas matérias-primas } \\
\text { - utilização de novos processos } \\
\text { - utilização de novos equipamentos. }\end{array}$ \\
\hline Atualização de mão-de-obra: & $\begin{array}{l}-59,7 \% \text { do total de funcionários receberam algum tipo de treinamento } \\
\text { entre } 2002 \text { e } 2003\end{array}$ \\
\hline $\begin{array}{l}\text { Fontes de informação } \\
\text { tecnológica: }\end{array}$ & $\begin{array}{l}\text { - feiras e congressos, revistas especializadas, contato com os clientes } \\
\text { e- contato com outros empresários }\end{array}$ \\
\hline $\begin{array}{l}\text { Fontes de informação } \\
\text { tecnológica: }\end{array}$ & $\begin{array}{l}\text { - feiras e congressos, revistas especializadas, contato com os clientes e } \\
\text { contato com outros empresários }\end{array}$ \\
\hline Formulação de estratégias: & $\begin{array}{l}\text { - aumento de competitividade, novas exigências dos clientes, } \\
\text { elevação dos custos dos insumos básicos e dificuldades de } \\
\text { financiamento/altas taxas de juros. }\end{array}$ \\
\hline
\end{tabular}

Fonte: Elaboração própria - a partir de uma amostra de empresas associadas ao SIMA

Os principais obstáculos para o avanço tecnológico são: insuficiência de incentivos fiscais e financeiros (25\%), disponibilidades financeiras próprias (23\%), instabilidade do mercado $(17,7 \%)$ e dificuldade de acesso a institutos financeiros $(15,6 \%)$. Percebe-se que a maior dificuldade para o avanço tecnológico é a questão financeira, seja o acesso ao crédito, as disponibilidades próprias ou a insuficiência de incentivos fiscais e financeiros.
O cluster de Arapongas (PR) e região caracteriza-se por ter um bom índice de investimento em atualização de mão-de-obra. 59,7\% do total de funcionários das empresas pesquisadas, receberam algum tipo de treinamento entre 2002 e 2003. Pyke (1992) aponta que os clusters caracterizam-se por dois pólos antagônicos, (a competição e a cooperação), mas ambas contribuem para o desenvolvimento das empresas. Do total de empresas pesquisadas, 55,6\% não têm conhecimento de projetos cooperativos, porém se verifica uma atuação 
bastante expressiva do Sindicato Patronal (SIMA) e do CETEC, uma organização não-governamental, criada pelos empresários para administrar os problemas de resíduos sólidos e líquidos das empresas. Quanto às fontes de informação tecnológica, as empresas utilizam principalmente feiras e congressos $(22,8 \%)$, revistas especializadas (21\%), contato com clientes $(17,3 \%)$ e contato com outros empresários $(14,2 \%)$.

Os novos produtos e modelos nas empresas pesquisadas são desenvolvidos na própria empresa e em $77,8 \%$ das empresas pesquisadas por solicitação de clientes. $\mathrm{O}$ fato de os produtos serem desenvolvidos na própria empresa, justifica-se pela existência de funcionários executando tarefas de P\&D em 51,1\% das empresas pesquisadas, mas, em muitos casos, isso é sinônimo de cópia.

A vocação do cluster de Arapongas (PR) e região é de atender o mercado brasileiro $(89,7 \%)$, destinando somente $10,3 \%$ da sua produção para a exportação. Os produtos são $66 \%$ médios, $22 \%$ populares e $12 \%$ de luxo. Os itens que mais influenciam a formulação de estratégias são o aumento da competitividade $(26,4 \%)$, a exigência dos consumidores/clientes $(24,8 \%)$, a elevação dos custos dos insumos básicos $(13,2 \%)$ e as dificuldades de financiamento/altas taxas de juros $(11,6 \%)$.As principais barreiras para exportar os produtos para as empresas pesquisadas são: o desconhecimento do mercado $(24,3 \%)$, a falta de incentivos governamentais $(17,9 \%)$, as tarifas e os impostos elevados $(14,1 \%)$, e os canais de comercialização inadequados (11,5\%). A disposição das empresas pesquisadas em não se associar a outras empresas para atuar em outros mercados pode impedir o seu crescimento e a sua expansão, dadas as inúmeras vantagens de uma associação entre empresas para atingir a um objetivo comum.

\section{Análise do Cluster Bento Gonçalves (RS)}

No cluster de Bento Gonçalves (RS), $100 \%$ das empresas pesquisadas atua no mercado há mais de 10 anos e têm em média 16 anos de atividade. O capital de origem das empresas pesquisadas é
$100 \%$ do Rio Grande do Sul e os principais produtos comercializados são: kits de cozinha $(26,6 \%)$, jogos de quarto $(20 \%)$, estofados $(20 \%)$, armários (13,3\%), e rack/estante (13,3\%).

Considerando o total de funcionários nas empresas pesquisadas, $66,7 \%$ das empresas têm entre 20 a 99 funcionários, $26,7 \%$ entre 100 a 499 funcionários, e 6,6\% entre 5 a 19 funcionários. Desses, $14,65 \%$ tem funções administrativas, $84,27 \%$ atuam na produção, e 1,08\% em Projetos e $P \& D, 66,7 \%$ das empresas pesquisadas não tem pessoal próprio atuando em P\&D. Em 64,3\% das empresas, o faturamento é de até $\mathrm{R} \$ 12$ milhões, e em $21,5 \%$ entre $\mathrm{R} \$ 12$ a 60 milhões ao ano.

O grau de instrução dos funcionários nas empresas pesquisadas é bom, pois 53\% têm escolaridade a partir do segundo grau completo ( $7,1 \%$ o superior incompleto, e $5,3 \%$ o superior completo) e $47 \%$ têm o segundo grau completo. O treinamento dos funcionários ocorre em $61 \%$ das empresas pesquisadas na própria empresa (fora do processo de trabalho), e em 27,8\% na empresa (no próprio processo de trabalho), o que totaliza $88,8 \%$ dos treinamentos realizados dentro das empresas.

Um percentual considerável de empresas pesquisadas $(76,5 \%)$ utiliza alguma norma técnica, e as principais são ISO9000 e 5S. Em relação a técnicas de organização (gestão da produção), $100 \%$ das empresas entrevistadas utilizam alguma técnica, as mais utilizadas são células de produção e rodízio. Para a solução de problemas tecnológicos, elas utilizam a pesquisa e o desenvolvimento na empresa, ou em universidades e institutos, associações de empresas, fornecedores e assessoria externa.

Com relação às condições atuais dos seus equipamentos, para $66,7 \%$ eles são parcialmente atualizados, e para $33,3 \%$ são totalmente atualizados. Os principais equipamentos utilizados pelas empresas pesquisadas são: linha de pintura $(54,5 \%)$, centros de usinagem $(27,5 \%)$, estufas 
(9\%) e computadores (9\%). Os principais obstáculos para o avanço da capacitação tecnológica são: instabilidade de mercado $(25,9 \%)$, insuficiência de incentivos fiscais e financeiros (25\%), dificuldade de acesso a institutos financeiros $(22,3 \%)$ e insuficiência de disponibilidades financeiras próprias $(18,5 \%)$.

Os principais avanços tecnológicos de produto e de matéria-prima adotados nos últimos anos pelas empresas pesquisadas foram: design e modelos, MDF, e pintura (tinta a pó, novas tintas, pintura UV e equipamentos).Os fatores importantes que levaram as empresas a adotarem tais avanços foram a busca por redução de custos (50\%), a busca por mercados externos e solicitações de clientes do mercado brasileiro.

O cluster de Bento Gonçalves (RS) caracterizase por ter um bom índice em atualização de mãode-obra, pois $58,15 \%$ do total de funcionários das empresas entrevistadas receberam algum tipo de treinamento entre 2002 e 2003.

Os projetos cooperativos são bastante conhecidos nas empresas pesquisadas, $54,5 \%$ têm conhecimento de projetos cooperativos, sendo $18,1 \%$ projetos entre empresa e instituições de pesquisa e $36,4 \%$ com associações de empresas. DeBresson (1996) afirma que as empresas têm desenvolvido estratégias de integração na cadeia produtiva por meio de alianças, joint ventures e consórcios, com o objetivo de obter acesso a novos mercados e complementar os conhecimentos e incrementar o processo de aprendizado. O Quadro 2 apresenta uma síntese das características do pólo gaúcho.

As principais fontes de informação tecnológica utilizadas pelas empresas pesquisadas são as feiras e congressos, as revistas especializadas e as visitas a empresas (com realce para a utilização de consultoria especializada), e os contatos com clientes. Os novos produtos e modelos são desenvolvidos em $81,2 \%$ das empresas pesquisadas na própria empresa e em $12,5 \%$ por especialistas contratados.

A origem da principal matéria-prima utilizada pelas empresas pesquisadas é: $40 \%$ do próprio Estado, 25\% de outras regiões do Brasil, 20\% de outros Estados da região e 15\% do Exterior. Os equipamentos utilizados pelas mesmas empresas têm origem: $35 \%$ no exterior, $30 \%$ no próprio estado, e o restante são produtos oriundos de outros estados. No caso de aquisição de novos equipamentos, o determinante em $32 \%$ das empresas pesquisadas foi o aumento da produtividade, em $28 \%$, qualidade dos produtos e em $24 \%$, lançamento de novos produtos.

O cluster de Bento Gonçalves (RS) tem bom desempenho exportador. $29 \%$ das empresas pesquisadas exportam, $45,2 \%$ atendem ao mercado nacional, $16,1 \%$ operam exclusivamente no mercado estadual e 9,7\% atendem ao mercado regional. Os produtos desse cluster são 53,3\% médios, $26,7 \%$ de luxo e $20 \%$ populares. As estratégias utilizadas pelas empresas são influenciadas em 28,6\% o aumento da competitividade, em $22,9 \%$ pelas exigências dos clientes, em $17,1 \%$ pela elevação dos custos dos insumos básicos, e em $14,3 \%$ pela redução do mercado interno.

As principais barreiras enfrentadas pelas empresas pesquisadas para exportar os seus produtos são: em 26,7\%, a oscilação do dólar; em $20 \%$, a concorrência acirrada. Salientam-se também os canais de comercialização inadequados, desconhecimento do mercado e falta de incentivos governamentais. Das empresas pesquisadas, $60 \%$ não pretende associar-se a outras empresas para atuar em outros mercados, apesar de considerar que parcerias são boas e levam à conquista de bons resultados. 
Quadro 2. Resumo da Análise Cluster de Bento Gonçalves (RS)

\begin{tabular}{|c|c|}
\hline Principais Produtos: & $\begin{array}{l}\text { Kits de cozinha, jogos de quarto, estofados, armários, } \\
\text { rack/estantes. }\end{array}$ \\
\hline Normas técnicas administrativas: & $\begin{array}{l}76,5 \% \text { utilizam alguma norma técnica (principais: ISO } \\
9000 \text { e } 5 \mathrm{~S} \text { ) }\end{array}$ \\
\hline Normas Técnicas de Produção: & $\begin{array}{l}\text { 100\% utiliza técnicas de produção } \\
\text { (principais: círculo de controle de qualidade, célula de } \\
\text { produção e just in time) }\end{array}$ \\
\hline $\begin{array}{l}\text { Solução de problemas } \\
\text { tecnológicos: }\end{array}$ & $\begin{array}{l}\text { - P \& D na empresa , universidades e institutos, } \\
\text { associações de empresas, } \\
\text { fornecedores e assessoria externa }\end{array}$ \\
\hline $\begin{array}{l}\text { Condições atuais dos } \\
\text { equipamentos: }\end{array}$ & $66,7 \%$ consideram parcialmente atualizados. \\
\hline $\begin{array}{l}\text { Principais obstáculos para o } \\
\text { avanço tecnológico: }\end{array}$ & $\begin{array}{l}\text { - } \text { instabilidade de mercado, insuficiência de } \\
\text { incentivos fiscais e financeiros, } \\
\text { - dificuldade de acesso a investimentos financeiros } \\
\text { - disponibilidades financeiras próprias. }\end{array}$ \\
\hline Principais avanços tecnológicos: & $\begin{array}{l}\text { - design e modelos } \\
\text { - MDF } \\
\text { - pintura (tinta a pó, novas tintas, pintura UV e } \\
\text { equipamentos) }\end{array}$ \\
\hline Atualização de mão-de-obra: & $\begin{array}{l}58,15 \% \text { do total de funcionários receberam algum } \\
\text { treinamento entre } 2002 \text { e } 2003\end{array}$ \\
\hline $\begin{array}{l}\text { Fontes de informação } \\
\text { tecnológica: }\end{array}$ & $\begin{array}{l}\text { - feiras e congressos, revistas especializadas e } \\
\text { visitas a empresas }\end{array}$ \\
\hline $\begin{array}{l}\text { Origem da principal Matéria - } \\
\text { Prima: }\end{array}$ & $\begin{array}{l}40 \% \text { do próprio estado e } 25 \% \text { de outras regiõe s do } \\
\text { Brasil }\end{array}$ \\
\hline Origem dos equipamentos: & $\begin{array}{l}35 \% \text { exterior, } 30 \% \text { do próprio estado e } 25 \% \text { outras } \\
\text { regiões do Brasil }\end{array}$ \\
\hline Mercado atendido: & $\begin{array}{l}\text { mercado nacional com considerável parcela da produção } \\
\text { destinada á exportação. }\end{array}$ \\
\hline Formulação de estratégias: & $\begin{array}{l}\text { - aumento de competi tividade, maiores exigências } \\
\text { dos clientes, } \\
\text { - elevação de custos dos insumos básicos e redução } \\
\text { do mercado interno. }\end{array}$ \\
\hline
\end{tabular}

Fonte: Elaboração própria - a partir da amostra de empresas associadas ao sindicato

\section{Análise do cluster Rio Negrinho (SC)}

Das empresas pesquisadas no cluster de Rio Negrinho (SC), 70\% atuam no mercado há mais de 10 anos, e em média têm 16 anos de atividade. $\mathrm{O}$ capital de origem das empresas pesquisadas é $100 \%$ do próprio Estado. Os principais produtos das indústrias moveleiras pesquisadas de Rio Negrinho (SC) são: $31,2 \%$ estofados, $25 \%$ mesas e cadeiras, $18,7 \%$ kits de cozinha e $12,5 \%$ rack/estante.
Nas empresas pesquisadas, $50 \%$ têm entre 5 a 19 funcionários, $30 \%$ tem entre 20 a 99 funcionários, e $20 \%$ tem entre 100 e 499 funcionários. Do total de funcionários, $87,35 \%$ trabalham na produção, $11,65 \%$ na administração e 1\% em Projeto/P\&D. Em 20\% das empresas, há funcionários atuando em $\mathrm{P} \& \mathrm{D}$. Na maioria das empresas (80\%), o faturamento é de até $\mathrm{R} \$$ 12 milhões ao ano. Ograu de instrução do pessoal ocupado é: $54,22 \%$, segundo grau incompleto; $42,70 \%$, 
segundo grau completo, e 3\%, superior completo e incompleto. As principais formas de treinamento utilizadas nas empresas pesquisadas são: $45,5 \%$ na empresa (fora do processo de trabalho), e 27,2\% na empresa (no próprio processo de trabalho). Apenas 33,3\% das empresas pesquisadas em Rio Negrinho (SC) utilizam alguma norma técnica, em geral ligada à questão da qualidade, como o 5S. 44,4\% dizem ter conhecimento e não as utilizam, porém mostram intenção de utilizar no futuro. Quanto às técnicas de organização, $20 \%$ usa o círculo de controle de qualidade, $10 \%$ usa o controle estatístico de processo, $20 \%$ usam o rodízio e $40 \%$ citam o 5 S como técnica de organização utilizada.

Os principais avanços tecnológicos de produto e de matéria-prima adotados nos últimos anos pelas empresas pesquisadas são: painéis de pinus maciço e melhorias no processo e em equipamentos (que

Quadro 3. Resumo da Análise do Cluster Rio Negrinho (SC) reflete na qualidade e produtividade).Os fatores importantes que levaram as empresas pesquisadas a adotar mudanças foram a busca por redução de custos (50\%), a busca por mercados externos $(25 \%)$ e as solicitações de clientes do mercado brasileiro (25\%). Para solucionar os problemas tecnológicos, as empresas pesquisadas utilizam principalmente a pesquisa e desenvolvimento na empresa, empresas de projeto e consultores nacionais, e fornecedores. Quanto às condições atuais dos equipamentos, $80 \%$ das empresas pesquisadas os consideram parcialmente atualizados. Os principais obstáculos para o avanço da capacitação tecnológica são a dificuldade de acesso a institutos financeiros e a instabilidade do mercado; foram também citadas a insuficiência de: incentivos fiscais, incentivos financeiros e disponibilidades financeiras próprias. $\mathrm{O}$ quadro 3 apresenta um resumo das características do pólo catarinense:

\begin{tabular}{|c|c|}
\hline Principais Produtos: & Estofados, mesas e cadeiras, kits de cozinha, racks/estante. \\
\hline $\begin{array}{l}\text { Normas técnicas } \\
\text { administrativas: }\end{array}$ & $33,3 \%$ utilizam alguma norma técnica $(5 \mathrm{~S})$ \\
\hline Normas Técnicas de Produção: & $\begin{array}{l}90 \% \text { utilizam normas técnicas de produção (principais: círculo de } \\
\text { controle de qualidade, controle estatístico de processo, rodízio, } 5 \mathrm{~S} \text { ). }\end{array}$ \\
\hline $\begin{array}{l}\text { Solução de problemas } \\
\text { tecnológicos: }\end{array}$ & $\begin{array}{l}\text { - P\& D na empresa , empresas de projetos, consultores } \\
\text { nacionais e fornecedores }\end{array}$ \\
\hline $\begin{array}{l}\text { Condições atuais dos } \\
\text { equipamentos: }\end{array}$ & $80 \%$ consideram seus equipamentos parcialmente atualizados \\
\hline $\begin{array}{l}\text { Principais pontos críticos } \\
\text { relacionados á produção: }\end{array}$ & $\begin{array}{l}\text { - Preço da matéria-prima; } \\
\text { - mão-de-obra pouco qualificada. }\end{array}$ \\
\hline $\begin{array}{l}\text { Principais obstáculos para o } \\
\text { avanço tecnológico: }\end{array}$ & $\begin{array}{l}\text { - Dificuldade de acesso a investimentos financeiros; } \\
\text { - instabilidade de mercado. }\end{array}$ \\
\hline $\begin{array}{l}\text { Principais avanços } \\
\text { tecnológicos: }\end{array}$ & $\begin{array}{l}\text { - Painéis de pinus maciço; } \\
\text { - melhora no processo e em equipamentos. }\end{array}$ \\
\hline Atualização de mão-de-obra: & $\begin{array}{l}60 \% \text { dos funcionários receberam algum tipo de treinamento entre } \\
2002 \text { e } 2003\end{array}$ \\
\hline $\begin{array}{l}\text { Fontes de informação } \\
\text { tecnológica: }\end{array}$ & $\begin{array}{l}\text { - Feiras e congressos, revistas especializadas, visitas a } \\
\text { empresas; } \\
\text { - contato com os clientes. }\end{array}$ \\
\hline $\begin{array}{l}\text { Origem da principal Matéria } \\
\text { Prima: }\end{array}$ & $46,7 \%$ próprio estado, $33,3 \%$ em outras regiões do Brasil. \\
\hline Origem dos equipamentos: & $61,5 \%$ próprio estado; $30 \%, 8 \%$ em outros estados da região. \\
\hline Mercado atendido: & Mercado nacional com forte ênfase na exportação $(27 \%)$. \\
\hline Canais de comercialização: & Representantes comerciais. \\
\hline Formulação de estratégias: & $\begin{array}{l}\text { - Aumento de competitividade, maiores exigências dos/ } \\
\text { clientes e; } \\
\text { dificuldades de financiamento, altas taxas de juros. }\end{array}$ \\
\hline
\end{tabular}

Fonte: Elaboração própria - a partir dos dados da amostra de empresas filiadas ao sindicato local 
Há treinamento e capacitação de mão-de-obra: $60 \%$ dos funcionários das empresas pesquisadas receberam algum tipo de treinamento entre $2002 \mathrm{e}$ 2003. Os projetos cooperativos desenvolvidos no cluster de Rio Negrinho (SC) são conhecidos por 78,6 \% das empresas pesquisadas, sendo 42,8\% projetos de Associação de Empresas. Com relação às fontes de informação tecnológica, as principais citadas pelas empresas pesquisadas são: feiras e congressos, revistas especializadas, visitas a empresas e contato com clientes.

Os novos produtos e modelos são desenvolvidos em $63,6 \%$ das empresas pesquisadas, na própria empresa, em 18,2\% adaptados pela empresa, e algumas empresas utilizam um especialista contratado para essa atividade. A matéria-prima utilizada pelas empresas tem origem no próprio Estado $(46,7 \%)$ e em outras regiões do Brasil .

Os principais equipamentos utilizados por essas empresas têm origem, em $61,5 \%$ das empresas pesquisadas, no próprio Estado, e em 30,8\% em outros estados da região. A aquisição de novos equipamentos tem influenciado, em $36,8 \%$ das empresas pesquisadas, $\mathrm{o}$ aumento da produtividade, em $31,6 \%$, qualidade dos produtos; em $21,1 \%$, lançamento de novos produtos; e em $10,5 \%$, necessidade de treinamento da mão-de-obra. Quanto ao serviço de atendimento ao cliente, $72,7 \%$ das empresas pesquisadas o fazem através de pessoal próprio e em 18,2\% através de terceiros.

O mercado atendido pelas empresas pesquisadas é em $72 \%$, o nacional, e, em $27 \%$, o mercado externo. Os produtos classificam-se em $73 \%$ médios, $18 \%$ de luxo e $9 \%$ populares. A formulação da estratégia da empresa é influenciada por aumento da competitividade, maiores exigências dos consumidores/clientes, e dificuldades de financiamento/altas taxas de juros. As principais barreiras para exportação são a falta de incentivos governamentais e a oscilação do dólar - também são citados: a qualidade do produto, o desconhecimento do mercado, a escala de produção e as tarifas e os impostos elevados. $70 \%$ das empresas não planejam se associar em função de iniciativas frustradas e da concorrência muito acirrada.

\section{Análise Comparativa entre os Pólos Moveleiros de Arapongas (PR) e Região, Rio Negrinho (SC) e Bento Gonçalves (RS) : Elos Horizontais, Verticais e Multilaterais}

Os clusters favorecem vínculos entre as firmas de natureza vertical (fornecedores, compradores e traders), de natureza horizontal (compras coletivas de insumos, parcerias, utilização em comum de alguns equipamentos) e de natureza multilateral (instituições públicas e privadas). O Quadro 4 resume as características dos três pólos analisados.

Quadro 4. Cluster Avançado Vs. Pólos Moveleiros

\begin{tabular}{|c|c|c|c|}
\hline $\begin{array}{c}\text { Cluster Avançado } \\
\text { Típico }\end{array}$ & $\begin{array}{c}\text { Arapongas }(\mathrm{PR}) \mathrm{e} \\
\text { região }\end{array}$ & Rio Negrinho (SC) & Bento Gonçalves (RS) \\
\hline $\begin{array}{l}\text { Aglomeração, com } \\
\text { especialização em } \\
\text { determinado ramo da } \\
\text { cadeia produtiva, com a } \\
\text { inclusão de setores } \\
\text { industriais para frente e } \\
\text { para trás. }\end{array}$ & $\begin{array}{l}\text { Aglomeração, } \\
\text { especialização em } \\
\text { determinado ramo da } \\
\text { cadeia produtiva, com } \\
\text { a inclusão de pequeno } \\
\text { número de setores } \\
\text { industriais para frente } \\
\text { e para trás. }\end{array}$ & $\begin{array}{l}\text { Aglomeração, } \\
\text { especialização em } \\
\text { determinado ramo da } \\
\text { cadeia produtiva, com a } \\
\text { inclusão de setores } \\
\text { industriais para frente e } \\
\text { para trás, com realce } \\
\text { à exportação. }\end{array}$ & $\begin{array}{l}\text { Aglomeração, } \\
\text { especialização em } \\
\text { determinado ramo da } \\
\text { cadeia produtiva, com a } \\
\text { inclusão de setores } \\
\text { industriais para frente e } \\
\text { para trás, realce para os } \\
\text { fornecedores de matéria- } \\
\text { prima. }\end{array}$ \\
\hline $\begin{array}{l}\text { Elevado grau de } \\
\text { inserção das atividades } \\
\text { econômicas no meio } \\
\text { social, cultural e } \\
\text { territorial. }\end{array}$ & $\begin{array}{l}\text { Elevado grau de } \\
\text { inserção das atividades } \\
\text { econômicas no meio } \\
\text { social, cultural e } \\
\text { territorial. }\end{array}$ & $\begin{array}{l}\text { Elevado grau de } \\
\text { inserção das atividades } \\
\text { econômicas no meio } \\
\text { social, cultural e } \\
\text { territorial. }\end{array}$ & $\begin{array}{l}\text { Elevado grau de inserção } \\
\text { das atividades econômicas } \\
\text { no meio social, cultural e } \\
\text { territorial, com ênfase na } \\
\text { educação profissional. }\end{array}$ \\
\hline
\end{tabular}


Camara, M. R. G; Serconi, L.

\begin{tabular}{|llll|}
\hline $\begin{array}{l}\text { Divisão do trabalho } \\
\text { entre as empresas } \\
\text { (integração horizontal) }\end{array}$ & $\begin{array}{l}\text { Integração vertical da } \\
\text { produção }\end{array}$ & $\begin{array}{l}\text { Integração vertical da } \\
\text { produção }\end{array}$ & $\begin{array}{l}\text { Integração vertical da } \\
\text { produção }\end{array}$ \\
\hline $\begin{array}{l}\text { Concorrência e } \\
\text { Cooperação }\end{array}$ & $\begin{array}{l}\text { Predomina a } \\
\text { concorrência }\end{array}$ & $\begin{array}{l}\text { Predomina a } \\
\text { concorrência }\end{array}$ & $\begin{array}{l}\text { Predomina a concorrência, } \\
\text { mas algumas atividades } \\
\text { são desenvolvidas em } \\
\text { conjunto }\end{array}$ \\
\hline $\begin{array}{l}\text { Densidade nas relações } \\
\text { institucionais }\end{array}$ & $\begin{array}{l}\text { Densidade nas } \\
\text { relações institucionais }\end{array}$ & $\begin{array}{l}\text { Densidade nas relações } \\
\text { institucionais }\end{array}$ & $\begin{array}{l}\text { Densidade nas relações } \\
\text { institucionais }\end{array}$ \\
\hline $\begin{array}{l}\text { Capacidade empresarial } \\
\text { e uma força de trabalho } \\
\text { especializada em } \\
\text { atividades pertinentes ao } \\
\text { setor }\end{array}$ & $\begin{array}{l}\text { Capacidade } \\
\text { força de trabalho } \\
\text { especializada em } \\
\text { atividades pertinentes } \\
\text { ao setor }\end{array}$ & $\begin{array}{l}\text { Capacidade empresarial, } \\
\text { forte ênfase ao } \\
\text { empreendedorismo } \\
\text { (exportação) e força de } \\
\text { trabalho especializada }\end{array}$ & $\begin{array}{l}\text { ênfase no } \\
\text { empreendedorismo e força } \\
\text { de trabalho especializada } \\
\text { formada por institutos } \\
\text { ligados ao pólo }\end{array}$ \\
\hline $\begin{array}{l}\text { Vantagens locacionais } \\
\text { superam } \\
\text { desvantagens }\end{array}$ & $\begin{array}{l}\text { Vantagens locacionais } \\
\text { superam desvantagens }\end{array}$ & $\begin{array}{l}\text { Vanta gens locacionais } \\
\text { superam desvantagens, } \\
\text { ênfase na logística }\end{array}$ & $\begin{array}{l}\text { Vantagens locacionais } \\
\text { superam desvantagens }\end{array}$ \\
\hline
\end{tabular}

Fonte: ROSA (1999), Câmara et al. (2003) e pesquisa realizada pelos autores

A análise das características de um cluster avançado típico, de acordo com Rosa (1999), permite verificar que há poucas possibilidades, no curto prazo, de os três pólos alcançarem um cluster avançado, pois os elos verticais e horizontais são fortes, mas os horizontais que envolvem cooperação em vários setores e estágios são fracos.
O quadro 5 apresenta as principais sugestões de política pública para a indústria moveleira, traçando um comparativo entre os três clusters pesquisados para a gestão da inovação, obras de apoio e infraestrutura tecnológica.

Quadro 5. Sugestões de política pública para a indústria Moveleira.

\begin{tabular}{|c|c|c|c|c|}
\hline & & Arapongas & $\begin{array}{c}\text { Rio } \\
\text { Negrinho }\end{array}$ & $\begin{array}{c}\text { Bento } \\
\text { Gonçalves }\end{array}$ \\
\hline \multirow{5}{*}{ 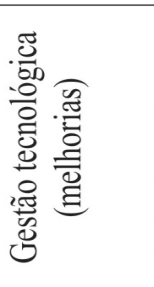 } & $\begin{array}{l}\text { Criação de escolas técnicas e laboratório } \\
\text { de P \& D }\end{array}$ & $\mathbf{X}$ & & $\mathbf{X}$ \\
\hline & $\begin{array}{l}\text { Disponibilização e acesso a recursos para } \\
\text { aquisicão de equipamentos }\end{array}$ & $\mathbf{X}$ & $\mathbf{X}$ & $\mathbf{X}$ \\
\hline & Isenção físcal & $\mathbf{X}$ & & \\
\hline & Redução da Carga Tributária & & $\mathbf{X}$ & \\
\hline & Juros Menores & & $\mathbf{X}$ & $\mathbf{X}$ \\
\hline \multirow{5}{*}{ 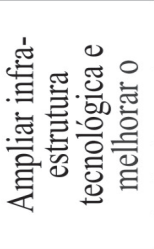 } & $\begin{array}{l}\text { Criação de laboratórios de P\&D e escolas } \\
\text { técnicas }\end{array}$ & $\mathbf{X}$ & & \\
\hline & $\begin{array}{l}\text { Disponibilização e acesso a } \\
\text { financiamentos com juros mais acessíveis }\end{array}$ & $\mathbf{X}$ & $\mathbf{X}$ & $\mathbf{X}$ \\
\hline & Incentivos do governo & $\mathbf{X}$ & & $\mathbf{X}$ \\
\hline & Ampliar linhas de financiamento & & $\mathbf{X}$ & $\mathbf{X}$ \\
\hline & Redução de impostos & & $\mathbf{X}$ & \\
\hline \multirow{6}{*}{ 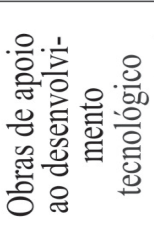 } & Ampliar linhas de Financiamento & $\mathbf{X}$ & & $\mathbf{X}$ \\
\hline & Juros Menores & $\mathbf{X}$ & $\mathbf{X}$ & $\mathbf{X}$ \\
\hline & Apoio às pequenas indústrias & & $\mathbf{X}$ & \\
\hline & Incentivos Fiscais & & $\mathbf{X}$ & \\
\hline & Planejamento para o Setor & & & $\mathbf{X}$ \\
\hline & Maior Atuação do Governo & & & $\mathbf{X}$ \\
\hline
\end{tabular}

Fonte: Elaboração própria 


\section{Conclusão}

O desenvolvimento de clusters em regiões em desenvolvimento traz benefícios econômicos e sociais, impulsionando o desenvolvimento da própria região. O estudo dos pólos moveleiros de Arapongas (PR) e região, Bento Gonçalves (RS) e Rio Negrinho (SC) possibilitou identificar as características de cada pólo, suas estratégias de crescimento, inovação e de gestão empresarial. As atuais estratégias adotadas pelas empresas são induzidas pelo aumento da competitividade e pelas novas exigências dos consumidores/clientes. As principais sugestões de política pública para esse setor são: criação de escolas técnicas e laboratório de $\mathrm{P} \& \mathrm{D}$, disponibilidade e acesso a recursos para aquisição de equipamentos, isenção fiscal e maiores incentivos do governo para que as indústrias possam desenvolver-se, ampliação de linhas de financiamento e juros menores, redução da carga tributária. ampliação das linhas de financiamento, planejamento para o setor e uma maior atuação do governo para promover o desenvolvimento dos pólos moveleiros. Quanto à possibilidade de formação de clusters avançados, pelas características levantadas nos clusters de Arapongas (PR) e região, Rio Negrinho (SC) e Bento Gonçalves (RS), conclui-se que é uma possibilidade remota. Para a existência de um cluster avançado, exige-se uma organização em nível bastante elevado do processo produtivo, da distribuição da produção entre pequenas empresas e também requer maior integração e cooperação entre grandes e pequenas empresas.

\section{Referências}

AAKER, D.A. Administração estratégica de mercado. 5.ed. Porto Alegre: Bookman, 2001.

AMATO NETO, J. Redes de cooperação produtiva e clusters regionais: oportunidades para as pequenas e médias empresas. São Paulo: Atlas/ Fundação Vanzolini, 2000.

CAMARA, M. R. G.; GUERREIRO, G. A.;
GIMENEZ, F. A. P.; DUTRA, I. S.; STEFANO, S. R.; PITELLI, M. M.; TORRES, N. P. P.; ALIGLERI, L. A.; PELISSON, C.; GOMES, R. C. O. Competitividade e a formação de cluster na indústria moveleira de Arapongas. In: MONTOYA, C.; ROSSETO, R.(Org.). Abertura econômica e competitividade no agronegócio brasileiro. Passo Fundo: UPF, 2002. v.1, p.263-284.

DeBRESSON, C.; SIRILLI, G.; LEMAY, J.; HU, X.; LUK, F. K. Innovative clusters in Italy (198185). In: DeBRESSON, C. (eds.) Economic Interdependence and Innovative Activity. Cheltenham: Edward Elgar, 1996. p.165-178.

EDQUIST, C. The systems of innovation approach and innovation policy: an account of the state of the art. DRUID CONFERENCE, Aalborg, 2001. Anais... Aalborg: Institutions and Public Policies, 2001. p.2-20.

FORAY, D.; LUNDVALL, B. The knowledge-based economy: from the economics of knowledge to the learning economy. In: OECD. Employment and growth in the knowledge-based economy. Paris, 1996.

GORINI, A. P. F. Panorama do setor moveleiro no Brasil, com ênfase na competitividade externa a partir do desenvolvimento da cadeia industrial de produtos de sólidos de madeira. BNDES Setorial, Rio de Janeiro, n.8, p.3-58, set. 1998.

KANTER, R. M. When giants learn cooperative strategies. Planning Review, Oxford, v.18, n.1, p.1522, jan./fev., 1990.

LASTRES, H. M. M.; CASSIOLATO, J. E. Novas políticas na era do conhecimento: o foco em arranjos produtivos e inovativos locais. Parcerias estratégicas, Brasília, v.17, p.5-29, fev. 2003.

LINS, H. N. Clusters industriais, competitividade e desenvolvimento regional: da experiência à necessidade de promoção. Estudos Econômicos, São 
Paulo, v.30, n.2, p.233-265, abr.jun. 2000.

LUNDVALL, B. A., JOHNSON B. The learning economy. Journal of Industry Studies, Sidney, v.1, n.2, p.23-42, 1984.

MALERBA, F. Sectoral systems of innovation and production. Research policy, Amsterdam, v.31, n.2, p.247-264, 2002.

PORTER, M. E. Clusters and the new economics of competition. Harvard Business Review, Boston, v.76, n.6, p.77, nov./dec. 1998.

PYKE, F. Industrial development through small firm cooperation: theory and practice. Genebra: International Labour Office, 1992.

ROELANDT, T. J.; HERTOG, P. Cluster analysis and cluster-based policy making: the state of the art. Paris: OECD PUBLICATIONS, 1999.

ROSA, A. L. T. Cluster setorial e competitividade da indústria de móveis de madeira nordestina. Fortaleza: Banco Nordeste, 1999. (Estudos Setoriais, v.5) 